\title{
Loss of $\mathrm{Ca}^{2+} /$ Calmodulin Kinase Kinase $\beta$ Affects the Formation of Some, But Not All, Types of Hippocampus-Dependent Long-Term Memory
}

\author{
Marco Peters, ${ }^{1}$ Keiko Mizuno, ${ }^{1}$ Laurence Ris, ${ }^{1,2}$ Marco Angelo, ${ }^{1}$ Emile Godaux,${ }^{2}$ and K. Peter Giese ${ }^{1}$ \\ ${ }^{1}$ Wolfson Institute for Biomedical Research, University College London, London, WC1E 6BT, United Kingdom, and ${ }^{2}$ Department of Neurosciences, \\ University of Mons-Hainaut, 7000 Mons, Belgium
}

\begin{abstract}
Long-term memory (LTM) requires activation of the transcription factor cAMP-responsive element binding protein (CREB). Signaling by the $\mathrm{Ca}^{2+}$ /calmodulin (CaM) kinase cascade has been implicated in CREB activation and memory consolidation processes in the hippocampus. The CaM kinase kinase $\beta$ isoforms belong to the CaM kinase cascade, and we have generated null mutant mice to investigate the role of these kinases in several forms of learning and memory. The null mutants were impaired in spatial training-induced CREB activation and spatial memory formation. Furthermore, the mutants lacked late, but not early, long-term potentiation at the hippocampal CA1 synapse, and they were impaired in LTM, but not short-term memory, for the social transmission of food preferences. We suggest that the CaM kinase kinase $\beta$ isoforms are required for the formation of hippocampal LTM. Surprisingly, however, these kinases were not needed for contextual, trace fear, and passive avoidance LTM. Our results demonstrate that different signaling processes underlie the formation of these types of hippocampal LTM.
\end{abstract}

Key words: CREB; gene targeting; hippocampus; learning and memory; long-term potentiation; signaling

\section{Introduction}

Several types of long-term memory (LTM) depend on the hippocampus. These include spatial, contextual, social transmission of food preferences (STFP), trace fear, and passive avoidance LTM (Morris et al., 1982; Kim and Fanselow, 1992; Phillips and LeDoux, 1992; Bunsey and Eichenbaum, 1995; McEchron et al., 1998; Cho et al., 1999; Taubenfeld et al., 1999, 2001; Huerta et al., 2000; Rampon et al., 2000; Alvarez et al., 2001; Anagnostaras et al., 2001; Winocur et al., 2001; Clark et al., 2002). It is believed that these LTMs engage different neuronal networks, but at the molecular level the formation of all of these LTMs requires the transcription factor cAMP-responsive element binding protein (CREB) (Bourtchouladze et al., 1994; Guzowski and McGaugh, 1997; Kogan et al., 1997; Gass et al., 1998; Taubenfeld et al., 2001; Kida et al., 2002; Pittenger et al., 2002). CREB is activated by phosphorylation at serine 133, and CREB activation, as well as induction of CRE-mediated transcription, has been observed during the formation of hippocampal LTM (Impey et al., 1998;

\footnotetext{
Received June 23, 2003; revised Sept. 5, 2003; accepted Sept. 6, 2003.

K.P.G. was supported by the Wellcome Trust (reference number 058440), a Human Frontier Science Young Investigator Award, and a Medical Research Council Career establishment grant; M.P. was supported by a Boehringe Ingelheim Fonds predoctoral fellowship; and E.G. was supported by the Belgian National Fund for Scientific Research (NFSR) and the Queen Elisabeth Fund for Medical Research. L.R. is a Scientific Research Worker of the NFSR. We thank Dr. R. Schoepfer for support at the beginning of this project, Dr. H. Sakagami for antibodies, and the UK Human Genome Mapping Project Resource Centre for providing the PAC library. We are grateful to H. Bito, T. V. P. Bliss, S Burton, P. F. Chapman, P. W. Frankland, C. A. Gadd, S.P. Hunt, T. Hussein, E. E. Irvine, F. Plattner, J. Trickett, J. Vernon, and C. H. Yeo for technical help and/or critical comments on previous versions of this manuscript.

Correspondence should be addressed to Karl Peter Giese, Wolfson Institute for Biomedical Research, University College London, Gower Street, London, WC1E 6BT, UK. E-mail: p.giese@ucl.ac.uk. Copyright $\odot 2003$ Society for Neuroscience $\quad$ 0270-6474/03/239752-09\$15.00/0
}

Taubenfeld et al., 1999; Athos et al., 2002; Mizuno et al., 2002; Colombo et al., 2003). It is not known, however, whether every distinct type of hippocampal LTM depends on CREB activation via an identical signaling pathway. Three known kinase pathways in the hippocampus activate CREB-dependent transcription: the mitogen-activated protein (MAP) kinase cascade, protein kinase A (PKA) signaling, and the $\mathrm{Ca}^{2+} /$ calmodulin (CaM) kinase cascade (for review, see Lonze and Ginty, 2002). The CaM kinase cascade consists of CaM kinase kinase $\alpha$, the CaM kinase kinase $\beta$ isoforms, CaM kinase I, and CaM kinase IV (Tokumitsu et al., 1995; Kitani et al., 1997; Anderson et al., 1998; Hsu et al., 2001) (for review, see Corcoran and Means, 2001). The CaM kinase kinases enhance the activity of CaM kinase I and CaM kinase IV, which regulate CREB activity in vitro (Bito et al., 1996; Anderson et al., 1998; Corcoran and Means, 2001; Lonze and Ginty, 2002; Takemoto-Kimura et al., 2003). Transgenic studies in Caenorhabditis elegans have shown that the homologues of CaM kinase I and a CaM kinase kinase are involved in the activation of CREB and CRE-mediated transcription in neurons in vivo (Kimura et al., 2002). Furthermore, Camk4 null mutants lack CREB activation after contextual fear conditioning (Wei et al., 2002).

Despite its well defined function as CREB activator in vitro, the role of the CaM kinase cascade in the formation of hippocampal LTM is little understood. Camk4 null mutants and dominantnegative CaM kinase IV transgenic mice were shown to be impaired in the formation of contextual LTM, but it is debated whether CaM kinase IV is important in spatial memory formation (Ho et al., 2000; Kang et al., 2001; Wei et al., 2002). To investigate the role of the CaM kinase kinase $\beta$ isoforms in learn- 
ing and memory, we inactivated the Camkk2 gene. We found that CaM kinase kinase $\beta$ isoforms are required for the formation of some, but not all, types of hippocampal LTM.

\section{Materials and Methods}

Generation of Camkk2 null mutants. EcoRI and BamHI fragments containing regions of the Camkk2 gene were subcloned from the 129/Sv mouse RPCI21 library (Osoegawa et al., 2000). A Camkk2 targeting construct was cloned such that exon 5 was flanked by a loxP site and a "floxed" NEO-gene and with the $3.0 \mathrm{~kb}$ EcoRI/SphI fragment and the 3.5 $\mathrm{kb}$ HpaI/SphI fragment as homology arms. Gene targeting in R1 embryonic stem (ES) (Nagy et al., 1993) was identified by Southern analyses, and after CRE recombination ES cell clones with null or floxed alleles were obtained. Germline chimeras, generated by blastocyst injections (Giese et al., 1998), were crossed with C57BL/6 mice, and homozygous mutants and control littermates were obtained from intercrosses of heterozygotes. Offspring were genotyped by PCR (primers: 5'-AAAGAAGCTGATCCGACAGG-3'， 5' -TTTTACAGATGGTCTAGCGTC-3'， 5' ACACTGCTAACTCCACATTCA-3'), and the mice were maintained and treated according to the Animals (Scientific Procedures) Act 1986, UK.

Immunoblots. For the analysis of protein expression, protein was isolated by standard procedures from adult forebrain, cerebellum, and hippocampus. For the phospho-CREB studies adult male mice (WT, $n=6$; mutant, $n=4$ ) were trained in the Morris water maze with four trials per day for $6 \mathrm{~d}$; after a probe trial on day 6 the mice were killed immediately. Hippocampal protein was isolated by using the following lysis buffer: 0.2 M NaCl, 0.1 м HEPES, $10 \%$ glycerol, $1 \%$ Triton X-100, and (in mм) 10 sodium pyrophosphate, 2 EDTA, 2 EGTA, Complete-EDTA-free protease inhibitor mixture tablet (Roche Diagnostics, Pleasanton, CA), 0.2 phenylarsine oxide, 0.1 molybdate, $10 \mathrm{NaF}, 2$ sodium pervanadate. Equal protein amounts were immunoblotted by using antibodies against $\beta$-Actin (Sigma, Poole, UK), CaMKK $\alpha$ (a gift from H. Sakagami, Sendai, Miyagi, Japan), CaMKK $\beta$ (m $\beta 4 D 8$; Sakagami et al., 2000), CaMKIV (Santa Cruz Biotechnology, Santa Cruz, CA), CREB, phospho-CREB (Cell Signaling, Beverly, MA), and synaptotagmin (Sigma). Horseradish peroxidase-conjugated secondary antibodies and a chemiluminescent detection system were used to visualize protein bands, which were quantified with a bio-imaging system (Quantity One, Bio-Rad, Hercules, CA).

Histology. A 14-month-old male Camkk2 null mutant and a control littermate under terminal anesthesia were perfused with $4 \%$ paraformaldehyde in PBS. Coronal brain sections, $40 \mu \mathrm{m}$ thick, were stained with toluidine blue.

Social transmission of food preferences. Male and female mice (3-7 months-old) balanced for sex were tested blind to genotype. No effect of sex was observed. The mice were studied in the Morris water maze 2 or more weeks before testing in this task. They were trained first to eat ground chow for $2 \mathrm{~d}$. In the delay version, demonstrator mice were food deprived ( $22 \mathrm{hr}$ ) and allowed to eat food scented with $0.5 \%$ cumin or $2 \%$ marjoram for $1 \mathrm{hr}$. Equal numbers of demonstrator mice from each group were allowed to eat either cumin- or marjoram-scented food. Subsequently, each demonstrator interacted with its cage mates, the observers, for $15 \mathrm{~min}$. The observers were food deprived and allowed to eat for $1 \mathrm{hr}$ scented food at $24 \mathrm{hr}$ after the interaction. A subgroup of the observers was retested in the immediate version. To avoid confounding effects of memory of the previously used scents, we used another scent pair ( $2 \%$ thyme and $1.5 \%$ turmeric). As in the delay version, the presented food was counterbalanced. Immediate testing was done in a similar way, except that observers and demonstrators were food deprived together, and testing was done immediately (within $5 \mathrm{~min}$ ) after the interaction. Observers had ad libitum access to water during the testing period. Observers that ate $<0.2 \mathrm{gm}$ of food were excluded from the experiment. WT or heterozygous mice were used as demonstrators. ANOVA was used for statistical analysis.

Morris water maze. Naïve male mice (2-6 months old) were studied blind to genotype in a setup shown to be hippocampus-dependent (Angelo et al., 2003). The diameter of the swimming pool was $1.5 \mathrm{~m}$, the platform diameter was $0.1 \mathrm{~m}$, and the water temperature was $22-24^{\circ} \mathrm{C}$. Two to six-month-old mutants and control littermates were tested in the hidden platform version of the Morris water maze. After $6 \mathrm{~d}$ of handling the mice were tested with four trials per day for $10 \mathrm{~d}$. The maximal trial length was $90 \mathrm{sec}$, and the intertrial interval was $60 \mathrm{sec}$. Probe trials were given at the end of training days 6 and 10 and then $7 \mathrm{~d}$ after the end of training. The mouse was placed on the platform for $60 \mathrm{sec}$. Then the platform was removed from the swimming pool. The mouse was put into the swimming pool at the opposite quadrant and allowed to swim for 60 sec. Video tracking and the HVS "water 2020" program were used to analyze swimming speed and search strategies. One-way ANOVA, oneway ANOVA on ranks (if data were not distributed normally), two-way ANOVA with repeated measures, and Tukey post hoc tests were used for statistical analysis.

Fear conditioning. Two- to eight-month-old mutants and control littermates were tested blind to genotype. Mice used for training were naïve and tested only once except for testing of cued conditioning, which was done after testing of contextual conditioning. We used males only for testing of $24 \mathrm{hr}$ and $14 \mathrm{~d}$ memory, and males and females balanced for sex for the other tests. No effect of sex was observed. For contextual and cued conditioning each mouse was placed into the conditioning chamber (Campden Instruments, Loughborough, UK) in a soundproof box; after a $120 \mathrm{sec}$ introductory period a tone $(80 \mathrm{~dB}, 2.8 \mathrm{kHz})$ was presented for $30 \mathrm{sec}$, the last $2 \mathrm{sec}$ of which coincided with a foot shock $(0.55 \mathrm{~mA})$. After $30 \mathrm{sec}$ the mouse was returned to its home cage. Contextual conditioning was tested by reexposing the mice to the chamber for $5 \mathrm{~min}$, and cued conditioning was tested by exposing the mice to a novel chamber for 3 min without tone presentation, followed by 3 min with tone presentation. In trace fear conditioning the mice received five tone-shock pairings, with $60 \mathrm{sec}$ exploration time before the pairings. The pairings consisted of $15 \mathrm{sec}$ tone presentations, followed by $30 \mathrm{sec}$ trace intervals terminating with a foot shock $(0.55 \mathrm{~mA}$ for $2 \mathrm{sec})$ and a $210 \mathrm{sec}$ rest period between pairings. Mice were tested in a novel chamber for $2 \mathrm{~min}$; after 1 min the training tone was presented for $15 \mathrm{sec}$. The behavior of the mice was videotaped, and freezing was assessed every $5 \mathrm{sec}$ (freezing was scored if no movements other than respiratory movements were detected within $2 \mathrm{sec}$ ); one-way ANOVA was used for statistical analysis.

Passive avoidance. Naïve mice (5-10 months old) balanced for sex were tested blind to genotype. No effect of sex was observed. Each mouse was placed individually into the lit compartment of an automated passive avoidance system (Ugo Basile, Comerio, Italy) and, after entering the dark compartment, was given a mild foot shock $(0.7 \mathrm{~mA}$ for $1 \mathrm{sec})$. For testing the mice were placed into the lit compartment; after $5 \mathrm{sec}$ the sliding door was opened, and the latency (maximum $300 \mathrm{sec}$ ) to enter the dark compartment was scored. One-way ANOVA with repeated measures was used for statistical analysis.

Rotarod. Naïve male mice (2-6 month old) were placed on a rotarod (Ugo Basile) constantly accelerating from 5 to $40 \mathrm{rpm}$ for maximally 5 $\mathrm{min}$; the time to fall was recorded. The training was for $4 \mathrm{~d}$ with two trials per day and an intertrial interval of $1 \mathrm{hr}$. Two-way ANOVA with repeated measures was used for statistical analysis.

Slice electrophysiology. The experiments were done blind to genotype. Transverse hippocampal slices ( $450 \mu \mathrm{m}$ ) from 9- to 12-month-old male mice were placed in a submerged recording chamber maintained at $30^{\circ} \mathrm{C}$ and perfused continuously with oxygenated artificial CSF (ACSF) at 3 $\mathrm{ml} / \mathrm{min}$. Bipolar tungsten microelectrodes (World Precision Instruments, Sarasota, FL) were used to stimulate Schaffer collaterals, and evoked field EPSPs (fEPSPs) were recorded in the stratum radiatum of the CA1 region with low-resistance $(2-5 \mathrm{M} \Omega$ ) glass microelectrodes filled with ACSF. Test stimuli were biphasic constant voltage pulses $(0.05$ msec per polarity) delivered every minute with an intensity adjusted to evoke an $\sim 33 \%$ maximal response. The ACSF contained (in $\mathrm{mM}$ ): 124 $\mathrm{NaCl}, 5 \mathrm{KCl}, 26 \mathrm{NaHCO}_{3}, 1.24 \mathrm{KH}_{2} \mathrm{PO}_{4}, 2.4 \mathrm{CaCl}_{2}, 1.3 \mathrm{MgSO}_{4}$, and 10 D-glucose and was bubbled with a gas mixture of $95 \% \mathrm{O}_{2} / 5 \% \mathrm{CO}_{2}$. Student's $t$ tests were used for statistical analysis.

\section{Results}

\section{Generation of Camkk2 null mutant mice}

In situ hybridizations showed that the mouse Camkk2 gene is expressed prominently in the hippocampus, neocortex, and cerebellum (data not shown), similar to the expression pattern in 
rats (Anderson et al., 1998; Sakagami et al., 2000; Nakamura et al., 2001). We inactivated the mouse Camkk2 gene by deleting exon 5 (Fig. $1 A, B$ ). Exon 5 encodes part of the catalytic domain, which is common to all CaM kinase kinase $\beta$ isoforms (Hsu et al., 2001), and its removal results in a frame shift generating a premature stop codon. Immunoblot analyses confirmed the null mutation (Fig. 1C,D). Furthermore, the loss of the CaM kinase kinase $\beta$ isoforms did not lead to a compensatory change in expression of CREB (data not shown), CaM kinase kinase $\alpha$, or CaM kinase IV isoforms (Fig. 1C,D).

\section{Basic characterization and motor learning of Camkk2 null mutants}

The null mutants were obtained in a Mendelian ratio $\left(n=175 ; \chi^{2}=1.3 ; p>0.50\right)$, and the appearance of adult mutants was indistinguishable from that of wild-type (WT) littermates. Both male (WT, $n=11$, $28.1 \pm 2.1$ gm; mut, $n=11,28.7 \pm 2.3 \mathrm{gm}$; $p=0.53$ ) and female (WT, $n=10,21.4 \pm$ 1.4 gm; mut, $n=13,21.9 \pm 1.8$ gm; $p=$ 0.43 ) null mutants had normal body weight at 9-10 weeks of age. No obvious morphological abnormalities were observed in adult mutant brain (Fig. 1E; supplementary Fig. 1; available at www. jneurosci.org). This finding, together with the specific impairments in behavioral tasks (see below), indicated that the loss of the CaM kinase kinase $\beta$ isoforms did not cause severe developmental deficits. Interestingly, no apparent loss of cerebellar Purkinje cells was observed (Fig. $1 E$ ), contrary to what has been seen in one line of Camk4 null mutant mice [Ribar et al. (2000), but see Ho et al. (2000)]. Consistent with our observation, the Camkk2 null mutants were not impaired in motor learning on an accelerating rotarod (twoway ANOVA with repeated measures; effect of genotype, $F_{(1,18)}=0.39, p=0.54$; effect of training day, $F_{(3,54)}=26.1, p<$ 0.001 ; genotype $\times$ training interaction, $F_{(3,54)}=0.43, p=0.73$ ) (Fig. $\left.1 F\right)$. These results suggested that the phenotype of the Camkk2 null mutant mice was sufficiently specific to investigate mechanisms underlying learning and memory.

\section{Impaired LTM for the STFP in the Camkk2 null mutants}

LTM, but not short-term memory (STM), in the STFP task requires the transcription factors CREB and zif268 (Kogan et al., 1997; Jones et al., 2001). We found that the loss of the CaM kinase kinase $\beta$ isoforms also impaired LTM for the STFP (Fig. 2A,B). When tested $24 \mathrm{hr}$ after the interaction with the demonstrator mice, mutants showed no preference for the cued food (cued, $0.30 \pm 0.05 \mathrm{gm}$; noncued, $0.27 \pm 0.06 \mathrm{gm}$; one-way ANOVA with food as variable, $\left.F_{(1,32)}=0.11, p=0.74\right)$. In contrast, WT mice

A

E

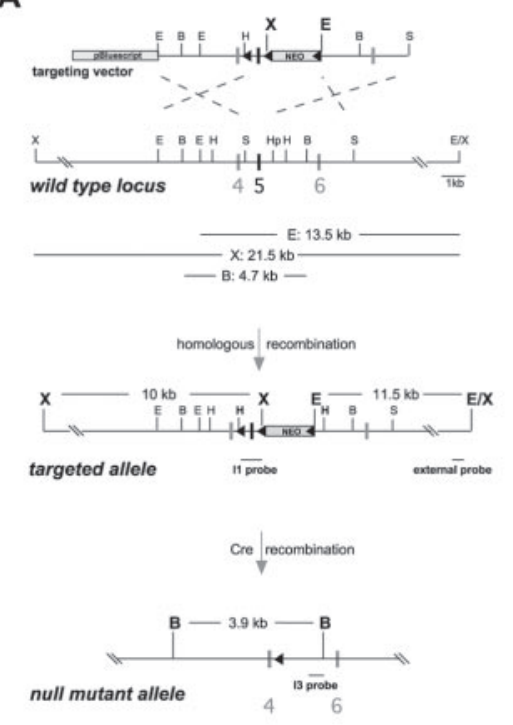

Figure 1. Generation of Camkk2 null mutant mice. $A$, Gene targeting. Exon 5 of the mouse Camkk2 gene was flanked by a loxP ; , Hpal:S, Sphl:X, Xbal. Bars indicate exons; triangles indicate loxP sites. B, Left, Southern analysis of a targeted ES cell we of an external probe. Targeted clones also were screened for partial gene duplication and nonhomologous . gross morphology in Camkk2 null mutants. Coronal sections stained with toluidine blue are shown. CA1/3, Area CA1/3 of the hippocampus; DG, dentate gyrus; $\mathrm{GL}$, granular layer of the cerebellum; $\mathrm{ML}$, molecular layer of the cerebellum; $\mathrm{PC}$, Purkinje cell. $F_{\text {, }}$ Normal motor learning on an accelerating rotarod in Camkk2 null mutant mice (means \pm SEM). The latency to fall did not differ between mutant $(n=10)$ and WT $(n=10)$ mice.

preferred the cued food (cued, $0.41 \pm 0.07 \mathrm{gm}$; noncued, $0.21 \pm$ $0.06 \mathrm{gm}$; one-way ANOVA with food as variable, $F_{(1,30)}=4.45$, $p<0.05)$. The two genotypes did not differ in the total amount of food eaten (one-way ANOVA with genotype as variable, $F_{(1,31)}=$ $0.28, p=0.60)$. In contrast with the impairment in the delay version, the Camkk2 null mutants were not impaired in the immediate version of the task (Fig. 2C,D). The mutants preferred the cued food when tested immediately after training (cued, $0.36 \pm 0.06$ gm; noncued, $0.19 \pm 0.03$ gm; one-way ANOVA with food as variable, $\left.F_{(1,24)}=5.94, p<0.05\right)$ as did the WT mice (cued, $0.35 \pm 0.04 \mathrm{gm}$; noncued, $0.17 \pm 0.04 \mathrm{gm}$; one-way 
A
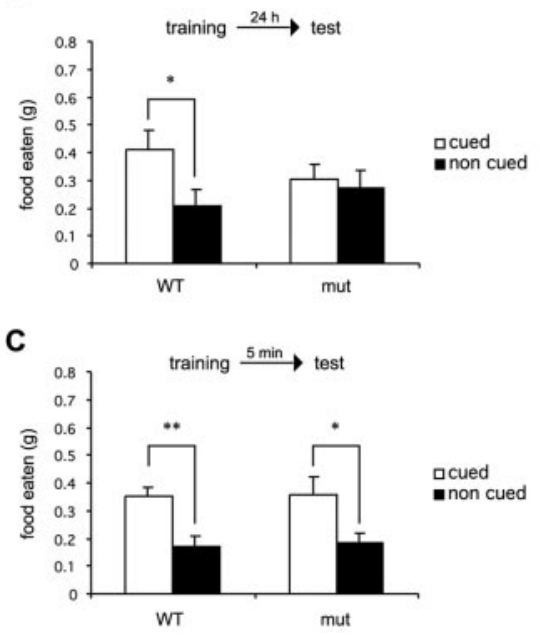

B

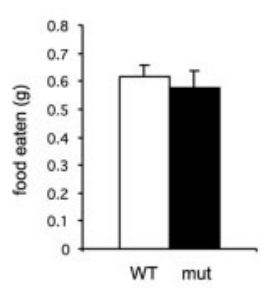

D

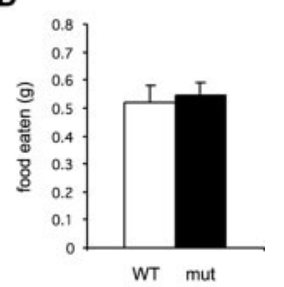

Figure 2. Long-term, but not short-term, memory for the social transmission of food preferences was impaired in Camkk2 null mutant mice. Means \pm SEM; ${ }^{*} p<0.05$; ${ }^{* *} p<0.01$. A, When tested $24 \mathrm{hr}$ after training, WT mice $(n=16)$ showed a significant preference for the cued food, whereas the mutants $(n=17)$ ate equal amounts of cued and noncued food. $B$, The total amount of food eaten during the delayed test did not differ between genotypes. $C$, Both mutant ( $n=13$ ) and WT mice $(n=14)$ preferred the cued food when tested 5 min after training. D, The total amount of food eaten during the immediate test did not differ between genotypes.

ANOVA with food as variable, $\left.F_{(1,26)}=12.32, p<0.01\right)$. As in the delay test, the total amount of food eaten did not differ between the genotypes (one-way ANOVA with genotype as variable, $\left.F_{(1,25)}=0.09, p=0.77\right)$. Normal STM of the STFP indicated that the Camkk2 null mutant mice were not impaired in olfaction or social interaction and that the impairment in the delay test must have resulted from a LTM deficit.

\section{Impaired spatial memory formation in the Camkk2 null mutants}

To investigate whether the CaM kinase kinase $\beta$ isoforms are required for spatial memory formation, we studied the Camkk2 null mutants and WT littermates in the hidden platform version of the Morris water maze (Fig. 3). The mice were trained with four trials per day for $6 \mathrm{~d}$, and the genotypes did not differ in latency to locate the platform (two-way ANOVA with repeated measures; effect of genotype, $F_{(1,21)}<0.01, p=0.97$; effect of training, $F_{(5,105)}=15.55, p<0.001$; genotype $\times$ training interaction, $F_{(5,105)}=1.54, p=0.18$ ) (Fig. $3 A$ ). This finding indicates that the mutants were not impaired in motivation, swimming abilities, and vision. Nonetheless, analysis of the acquisition data is not a good measure for spatial learning, because mice can learn alternative hippocampus-independent strategies to locate the hidden platform, such as circling with a particular radius. However, probe trials are a better assessment of spatial learning (Costa et al., 2001). The probe trials given at the end of training day 6 revealed that the Camkk2 null mutants were impaired in spatial learning. During these probe trials there was no difference between genotypes in average swimming speed (WT, $21.6 \pm 1.0$ $\mathrm{cm} / \mathrm{sec}$; mutants, $22.5 \pm 1.7 \mathrm{~cm} / \mathrm{sec}$; one-way ANOVA with genotype as variable, $\left.F_{(1,21)}=0.16, p=0.69\right)$ and time spent in the thigmotaxis zone (WT, $3.5 \pm 1.8 \%$; mutants, $2.3 \pm 1.3 \%$; oneway ANOVA with genotype as variable, $\left.F_{(1,21)}=0.27, p=0.61\right)$. Analysis of the quadrant search times showed that the mutants spent less time in the target quadrant than WT littermates (mutants, $30.9 \pm 5.2 \%$; WT, $47.0 \pm 5.2 \%$; one-way ANOVA with genotype as variable, $\left.F_{(1,21)}=4.80, p<0.05\right)$ and that the mu-

A

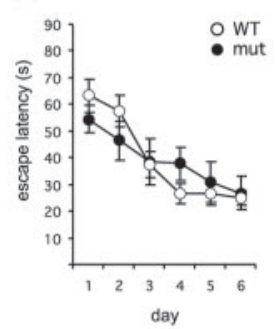

C

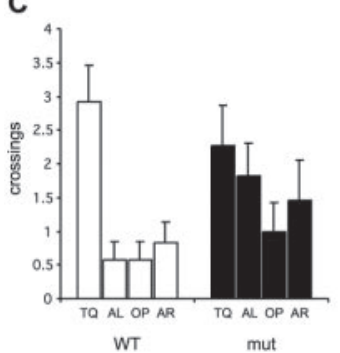

E

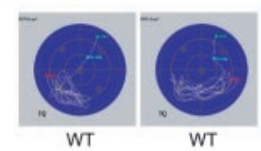

B

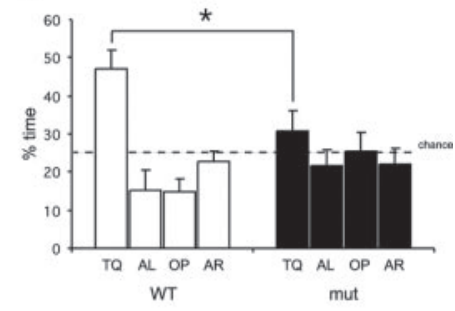

D
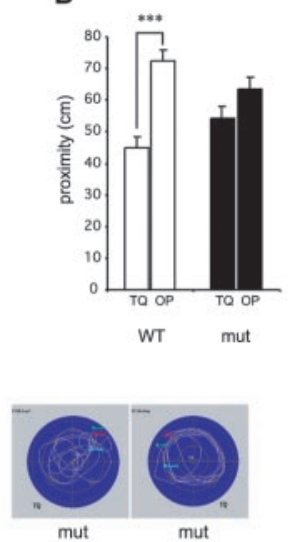

Figure 3. Impaired spatial memory formation in Camkk2 null mutant mice. Means \pm SEM; ${ }^{*} p<0.05$; ${ }^{* * *} p<0.001$. $A$, The time to reach the hidden platform did not differ between mutant $(n=11)$ and WT $(n=12)$ mice; both groups improved with training. $B$, The Camkk2 null mutant mice did not search selectively in a probe trial given after $6 \mathrm{~d}$ of training. Analysis of the search time showed that the mutant mice also spent less time in the target quadrant than did controls. TQ, Target quadrant; AL, adjacent left quadrant; OP, opposite quadrant; AR, adjacent right quadrant. C, WT mice crossed the target platform position more often than any other position in the pool. Mutants, in contrast, crossed the platform positions in all four quadrants equally often. D, Mutants searched equally close to the opposite quadrant, whereas WT controls searched in close proximity to the platform position in the target quadrant. $E$, Examples of search strategies during the probe trial used by WT and Camkk2 null mutant mice.

tants searched randomly, spending similar times in all quadrants (one-way ANOVA with quadrant as variable, $F_{(3,40)}=0.86, p=$ 0.47 ) in contrast with the WT littermates (one-way ANOVA with quadrant as variable, $F_{(3,44)}=17.25, p<0.001$ ) (Fig. $3 B, E$ ). The WT mice spent more time searching in the target quadrant than in any other quadrant (Tukey post hoc test; $p<0.001$ ). Analysis of platform crossings (ANOVA on ranks with quadrant as variable; mutants, $H_{(3,40)}=3.19, p>0.05$; WT, $\left.H_{(3,44)}=16.5, p<0.001\right)$ and the proximity measure (Gallagher et al., 1993) (one-way ANOVA with quadrant as variable; mutants, $F_{(3,40)}=1.22, p=$ 0.32 ; WT, $\left.F_{(3,44)}=15.07, p<0.001\right)$ confirmed that there was random searching by the mutants and selective searching by the WT littermates (Fig, 3C,D).

We trained all mice except for one WT and one mutant mouse for $4 \mathrm{~d}$ more, using four trials per day, and gave another two probe trials (Fig. 4). There was no difference in acquisition during these additional training days (data not shown). When a probe trial was given at the end of training day 10 , Camkk2 null mutants and WT littermates spent equal amounts of time searching in the target quadrant (mutants, $44.3 \pm 6.5 \%$; WT, $48.6 \pm 4.6 \%$; oneway ANOVA with genotype as variable, $\left.F_{(1,19)}=0.31, p=0.58\right)$ (Fig. $4 A$ ) and searched selectively according to search time (oneway ANOVA with quadrant as variable; mutants, $F_{(3,36)}=10.23$, $p<0.001$; WT, $\left.F_{(3,40)}=26.71, p<0.001\right)$, platform crossings (one-way ANOVA on ranks with quadrant as variable; mutants, 
A

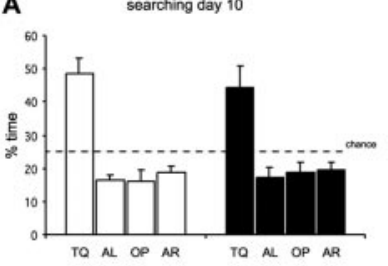

C plattorm crossings day 10

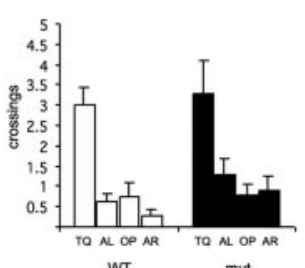

mut

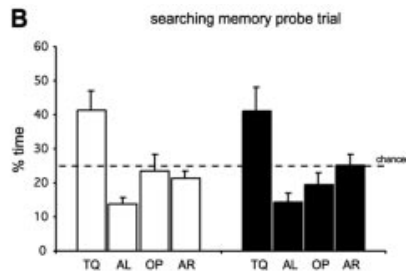

D proximily day 10

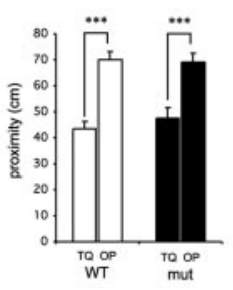

A

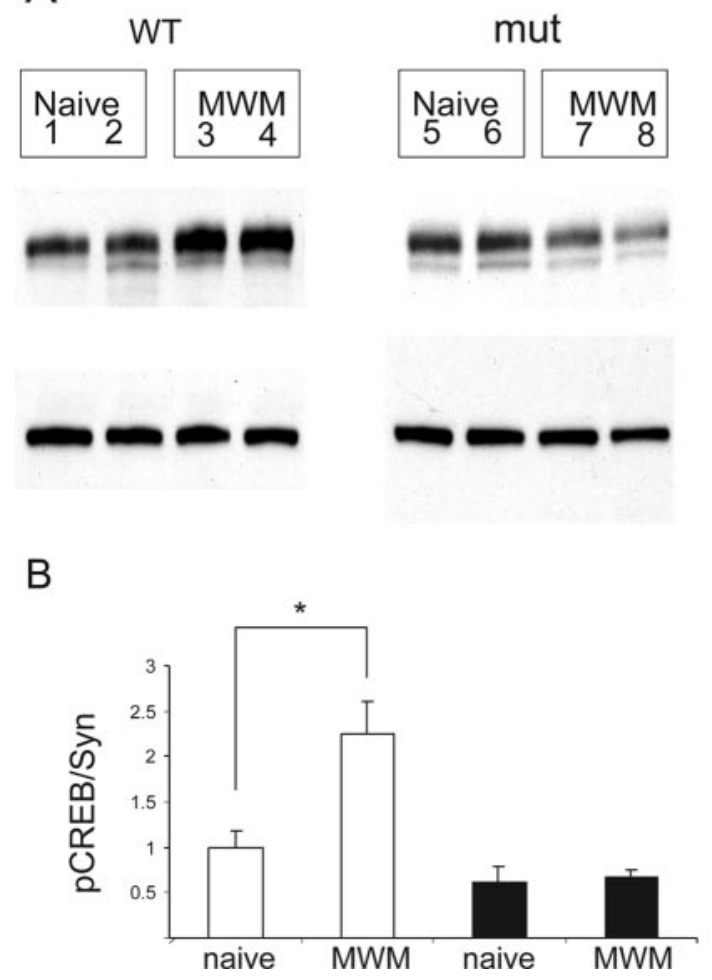

Figure 5. Hippocampal activation of CREB by spatial training was impaired in Camkk2 null mutant mice. $A$, Representative immunoblots showing the phosphorylation of CREB at Ser ${ }^{133}$ ( $p(R E B)$ in the hippocampus from naïve and trained mice. The mice were trained in the Morris water maze (MWM) for $6 \mathrm{~d}$ with 4 trials per day and were killed immediately after a probe trial. As a loading control an antibody against synaptotagmin (Syn) was used. B, Densitometric analysis was used for quantification of the signals in the immunoblots, and pCREB expression was normalized to synaptotagmin expression levels and as compared with naïve WT mice. pCREB expression increased after training in WT mice (naïve, $n=5$; trained, $n=6$ ), but not in Camkk2 null mutants (naïve, $n=4$; trained, $n=4$ ). Similar results were obtained when $\mathrm{pCREB} / \mathrm{CREB}$ expression was determined (data not shown). Means \pm SEM; ${ }^{*} p<0.05$.

studies, but these antibodies have a significant cross-reactivity with other phosphorylated CREB/ATF family members (BilangBleuel et al., 2002). For an analysis specifically directed to CREB phosphorylation at serine 133, we performed immunoblot studies with hippocampal lysates. In naïve WT mice and Camkk2 null mutants the levels of phospho-CREB were not significantly different (one-way ANOVA with genotype as variable, $F_{(1,7)}=2.19$, $p=0.18$ ) (Fig. 5). Water maze training induced a significant 2.2-fold increase in the levels of phospho-CREB in the hippocampus in WT mice (one-way ANOVA with training as variable, $\left.F_{(1,9)}=7.10, p<0.05\right)$, whereas no significant increase was observed in the Camkk2 null mutant mice (one-way ANOVA with training as variable, $F_{(1,6)}=0.06, p=0.82$ ) (Fig. 5). Thus the CaM kinase kinase $\beta$ isoforms are required for spatial traininginduced activation of CREB.

\section{Impaired late long-term potentiation at hippocampal CA1} synapses in the Camkk2 null mutants

Long-term potentiation (LTP) at the hippocampal Schaffer collateral CA1 synapse has been proposed as a cellular correlate of spatial learning and memory (Bliss and Collingridge, 1993; Chen and Tonegawa, 1997). Late LTP, but not early LTP, at this synapse depends on de novo protein synthesis and transcription (Frey et al., 1988; Nguyen et al., 1994). We investigated late LTP at the CA1 synapse in hippocampal slices from mutants and WT litter-
Impaired spatial training-induced activation of CREB in the
Camkk2 null mutants
It has been suggested that CREB is activated during spatial mem-
ory consolidation (Mizuno et al., 2002; Colombo et al., 2003). We
investigated whether the loss of the CaM kinase kinase $\beta$ isoforms
affected the activation of CREB during spatial memory formation
to cause the water maze impairments in the Camkk 2 null mu-
tants. Anti-phospho-serine 133 CREB antibodies are commonly
used to investigate CREB activation in immunocytochemical

Impaired spatial training-induced activation of CREB in the
Camkk2 null mutants
It has been suggested that CREB is activated during spatial mem-
ory consolidation (Mizuno et al., 2002; Colombo et al., 2003). We
investigated whether the loss of the CaM kinase kinase $\beta$ isoforms
affected the activation of CREB during spatial memory formation
to cause the water maze impairments in the Camkk 2 null mu-
tants. Anti-phospho-serine 133 CREB antibodies are commonly
used to investigate CREB activation in immunocytochemical 

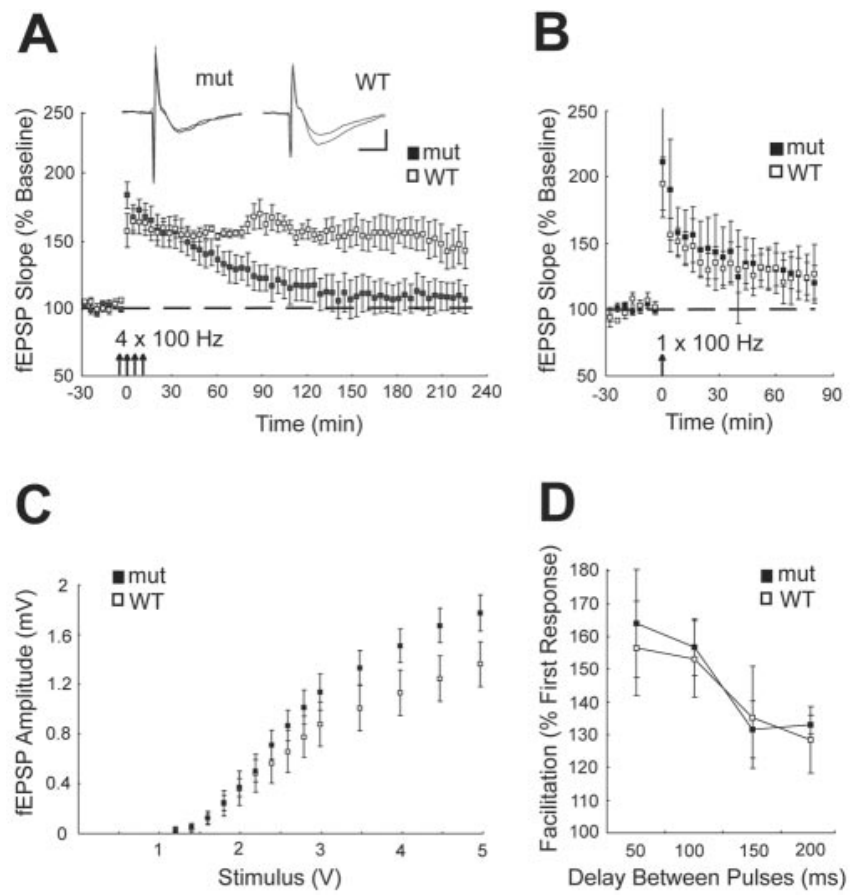

Figure 6. Late LTP, but not early LTP, was impaired in Camkk2 null mutant mice. Means \pm SEM. A, Four $100 \mathrm{~Hz}$ trains (1 sec) separated from each other by 5 min evoked late LTP in male WT ( $n=6$ mice), but not in mutant mice ( $n=6$ mice). Shown are sample fEPSP traces measured from area CA1 in WT (right) and mutant mice (left) $15 \mathrm{~min}$ before and $180 \mathrm{~min}$ after the tetanic trains. Each superimposed pair of sweeps was measured from a single slice. Calibration: $0.5 \mathrm{mV}$, $5 \mathrm{msec}$. The arrows indicate when the tetani were delivered. $B, 0$ ne $100 \mathrm{~Hz}$ train ( $1 \mathrm{sec}$ ) evoked the same levels of early LTP in WT ( $n=5$ mice) and mutant mice ( $n=5$ mice). C, Input- output curve of fEPSP amplitude ( $\mathrm{mV}$ ) versus stimulus $(\mathrm{V})$ at the Schaffer collateral pathway did not differ significantly between genotypes. $D$, Paired pulse facilitation did not differ between $\mathrm{mu}-$ $\operatorname{tant}(n=12$ slices, 6 mice) and WT mice ( $n=8$ slices, 6 mice).

mates (Fig. 6A). In WT mice a stimulus of four trains of $100 \mathrm{~Hz}$, $1 \mathrm{sec}$ tetanization at $5 \mathrm{~min}$ intervals increased the fEPSP slope 30 min later to $157 \%$ (difference from baseline, $p<0.01$ ), and this potentiation was maintained at 151,156 , and $155 \%$, for 1,2 , and $3 \mathrm{hr}$ after the trains, respectively $(p<0.01)$. In the Camkk 2 null mutants a stimulus of four $100 \mathrm{~Hz}$ trains increased the fEPSP slope $30 \mathrm{~min}$ later to $154 \%$ (difference from baseline, $p<0.01$ ). However, the potentiation in the Camkk2 null mutants was maintained for only $1 \mathrm{hr}$ (140\%; difference from baseline, $p<$ 0.01 ) and declined to baseline levels within $2 \mathrm{hr}$ after the trains (116\% at $2 \mathrm{hr}$ and $106 \%$ at $3 \mathrm{hr}$; differences from baseline, $p>$ $0.05)$. The potentiation up to $1 \mathrm{hr}$ did not differ between genotypes $(p>0.05)$, whereas after this time the two groups differed (90 min after the trains, $p<0.01 ; 120 \mathrm{~min}, p<0.01 ; 180 \mathrm{~min}, p<$ 0.01). The late LTP impairment in the Camkk2 null mutants was not associated with deficits in early LTP induced by a single 100 Hz tetanus (30 min after the trains, $p>0.05 ; 60 \mathrm{~min}, p>0.05 ; 90$ min, $p>0.05$ ) (Fig. $6 B$ ) or input-output relationships (difference for all stimulation intensities, $p>0.05$ ) (Fig. 6C) or paired pulse facilitation (difference at any interpulse interval, $p>0.05$ ) (Fig. 6D). Thus the CaM kinase kinase $\beta$ isoforms appear to be required specifically for the late phase of LTP at the hippocampal CA1 synapse.

Other forms of LTM are normal in the Camkk 2 null mutants Our findings that the CaM kinase kinase $\beta$ isoforms are required for spatial training-induced CREB activation and late LTP at the hippocampal CA1 synapse suggested that these kinases are im-
A

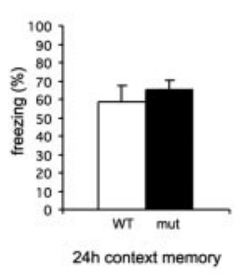

C

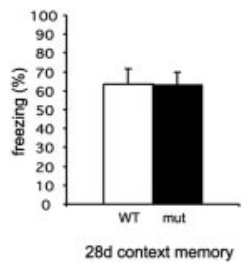

E

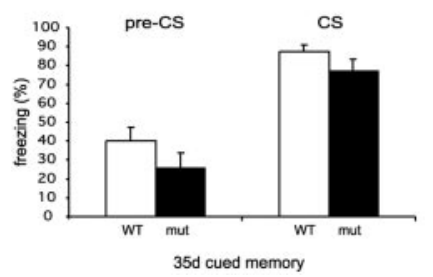

B

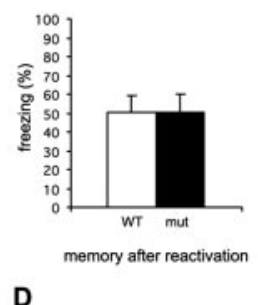

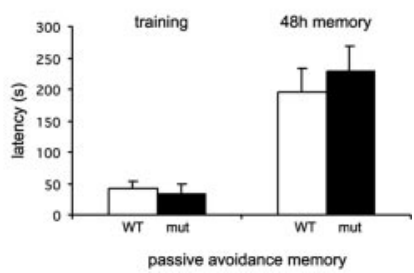

Figure 7. Long-term memory formation for cued, contextual, and trace fear conditioning and in a passive avoidance task were not impaired in Camkk2 null mutant mice. Means \pm SEM. $A$, Freezing did not differ between mutant $(n=10)$ and WT mice $(n=9) 24 \mathrm{hr}$ after contextual conditioning. $B$, Contextual long-term memory $24 \mathrm{hr}$ after memory reactivation, shown in $A$, was indistinguishable between genotypes. C, Contextual memory $28 \mathrm{~d}$ after training did not differ between the genotypes (mut, $n=9 ;$ WT, $n=9$ ). D, Freezing of mutant $(n=9)$ and WT mice $(n=9)$ did not differ $24 \mathrm{hr}$ after trace fear conditioning. Both groups increased their freezing response with the tone (CS) presentation (pre-CS, before tone presentation). $E_{\text {, Cued }}$ fear memory $35 \mathrm{~d}$ after training, $7 \mathrm{~d}$ after the context test shown in C, did not differ between the genotypes. $F$, The latency to enter the dark compartment in the passive avoidance task during and $48 \mathrm{hr}$ after training did not differ between mutant $(n=9)$ and WT mice $(n=12)$.

portant for consolidation of LTM not only in the STFP task and the Morris water maze but also in other hippocampal tasks. We first investigated the Camkk2 null mutants in contextual fear conditioning. Consolidation of contextual fear memory is hippocampus-dependent (Kim and Fanselow, 1992; Phillips and LeDoux, 1992; Anagnostaras et al., 2001), and after memory reactivation the hippocampus also is required (Debiec et al., 2002). Using ibotenic acid pretraining lesions of the dorsal and ventral hippocampus in 129B6F1 mice, we have confirmed that our contextual conditioning task is hippocampus-dependent (E. E. Irvine and K. P. Giese, unpublished data). Contextual LTM formation was not impaired in the Camkk2 null mutants (one-way ANOVA with genotype as variable; $24 \mathrm{hr}$ memory, $F_{(1,17)}=0.46$, $p=0.51$; reactivated memory, $F_{(1,17)}<0.01, p=0.90 ; 28 \mathrm{~d}$ memory, $F_{(1,16)}<0.01, p=0.94$ ) (Fig. $7 A-C$ ). Normal contextual conditioning in the null mutant mice was not attributable to saturation of the freezing response, because mutant and WT mice had significantly more freezing if trained with higher shock intensity (data not shown). Another form of hippocampusdependent LTM is tested in trace fear conditioning (McEchron et al., 1998; Huerta et al., 2000) whereby a conditioned stimulus (tone) is separated from an unconditioned stimulus (foot shock) by a time interval, the so-called trace interval. LTM of trace fear conditioning was normal in the Camkk2 null mutant mice (one- 
way ANOVA with genotype as variable; pre-CS, $F_{(1,17)}=2.01$; $p=0.18$; CS, $F_{(1,17)}<0.01 ; p=0.92$ ) (Fig. $7 D$ ). Furthermore, passive avoidance, which involves the hippocampus (Taubenfeld et al., 1999, 2001), was normal (one-way ANOVA with genotype as variable; training, $F_{(1,19)}=0.30, p=0.59 ; 48 \mathrm{hr}$ memory, $F_{(1,19)}=0.37, p=0.55$ ) (Fig. $7 F$ ) as well as amygdala-dependent cued fear conditioning (Phillips and LeDoux, 1992) (one-way ANOVA with genotype as variable; pre-CS, $F_{(1,16)}=1.68, p=$ 0.21 ; CS, $F_{(1,16)}=1.84, p=0.19$ ) (Fig. $7 E$ ). Taken together, our results show that the CaM kinase kinase $\beta$ isoforms are not required for the consolidation of all types of hippocampal LTM.

\section{Discussion}

We have used mouse molecular genetics to investigate the role of the CaM kinase kinase $\beta$ isoforms in hippocampal learning and memory. We showed that the loss of the CaM kinase kinase $\beta$ isoforms impaired spatial training-induced CREB activation in the hippocampus and that spatial memory formation blocked late, but not early, LTP at the hippocampal CA1 synapse and affected LTM, but not STM, in the STFP task. Taken together, our results suggest that the CaM kinase kinase $\beta$ isoforms are required specifically for the formation of LTM.

\section{Comparison of the roles of CaM kinase kinase $\beta$ and CaM kinase IV in learning and memory}

In vitro experiments have shown that the substrates of the CaM kinase kinase $\beta$ isoforms are CaM kinase I and CaM kinase IV, and these phosphorylation events enhance the kinase activities (Corcoran and Means, 2001). CaM kinase kinase $\alpha$ also can enhance the activity of CaM kinase I and CaM kinase IV in vitro (Tokumitsu et al., 1995; Takemoto-Kimura et al., 2003). In the hippocampus both CaM kinase kinase genes are expressed similarly (Anderson et al., 1998; Sakagami et al., 2000). The phenotype of the Camkk2 null mutants suggests that the functions of CaM kinase kinase $\alpha$ and CaM kinase kinase $\beta$ are not fully redundant in the hippocampus. Alternatively, both CaM kinase kinase gene products may have identical biochemical functions, and in this scenario the reduction of total CaM kinase kinase activity in the mutants would have caused the phenotype.

So far the role of CaM kinase I in learning and memory is unknown, but some studies have addressed the function of CaM kinase IV. At the hippocampal CA1 synapse CaM kinase IV is activated immediately after the induction of LTP (Kasahara et al., 2001), and it is required for an early phase of LTP (Ho et al., 2000). Interestingly, transgenic mice expressing a dominantnegative form of CaM kinase IV have a specific impairment in late CA1 LTP (Kang et al., 2001). This dominant-negative interference does not affect the basal activity of CaM kinase IV, but it reduces depolarization-induced CaM kinase IV activity. We found that the Camkk2 null mutants had an LTP phenotype similar to that of the dominant-negative CaM kinase IV transgenic mice. The simplest interpretation is that the CaM kinase kinase $\beta$ isoforms activate CaM kinase IV for establishing the late phase of CA1 LTP.

The role of CaM kinase IV in spatial learning and memory is debated because the Camk4 null mutants are normal (Ho et al., 2000) and the dominant-negative CaM kinase IV transgenic mice are impaired (Kang et al., 2001). In contrast, the role of CaM kinase IV in fear conditioning is better understood. CaM kinase IV contributes to fear conditioning-induced activation of CREB in amygdala and hippocampus, and the kinase is required for LTM, but not STM, in cued and contextual fear conditioning (Wei et al., 2002). Furthermore, the dominant-negative CaM ki- nase IV transgenic mice are impaired in contextual fear LTM (Kang et al., 2001). We showed that the Camkk2 null mutants had normal LTM in various versions of fear conditioning. Taken together, these findings predict that CaM kinase kinase $\alpha$, rather than CaM kinase kinase $\beta$ isoforms, activates CaM kinase IV during the formation of fear LTM.

\section{Activation of CREB during spatial memory formation}

We have confirmed previous findings (Mizuno et al., 2002; Colombo et al., 2003) that activation of CREB occurs in the hippocampus during spatial learning. The activation of CREB is thought to be important for spatial memory formation (Bourtchouladze et al., 1994; Pittenger et al., 2002), and our experiments confirm this hypothesis. We have shown that spatial training induces CREB activation in the hippocampus in WT mice. Furthermore, the loss of the CaM kinase kinase $\beta$ isoforms significantly delayed spatial memory formation and impaired CREB activation in the hippocampus. Most likely the CaM kinase kinase $\beta$ isoforms are needed to enhance the activity of CaM kinase IV to activate CREB. Alternatively, the CaM kinase kinase $\beta$ isoforms could impair a plasticity that is needed for the activation of CREB.

It is not known which signaling pathways activate during spatial learning. PKA, the MAP kinase cascade, and the CaM kinase cascade activate CREB in hippocampal neurons in vitro (for review, see Lonze and Ginty, 2002). Genetic or pharmacological interference with PKA or MAP kinase cascade signaling in the hippocampus impairs spatial memory formation (Abel et al., 1997; Blum et al., 1999; Selcher et al., 1999). However, it is not known whether these two signaling pathways activate CREB during spatial learning. In principle, the PKA and MAP kinase cascade blockade experiments could have affected other signaling routes to impair spatial LTM. We have shown that the CaM kinase kinase $\beta$ isoforms are needed for spatial memory formation and spatial training-induced CREB activation in the hippocampus. Thus our results show that signaling by the CaM kinase cascade is required for spatial memory formation, and they suggest that signaling by PKA and the MAP kinase cascade cannot compensate fully to activate CREB during spatial learning.

\section{Late LTP at the hippocampal CA1 synapse is not required for certain types of hippocampal LTM}

Late LTP at the hippocampal CA1 synapse and LTM depends on de novo translation and transcription (Frey et al., 1988; Nguyen et al., 1994; Silva and Giese, 1994). Therefore, the hypothesis that late CA1 LTP is a cellular correlate of LTM has attracted much attention. So far only a few mutant mouse lines having a sufficiently specific late LTP phenotype have been used to test this hypothesis. Transgenic mice expressing a dominant-negative form of PKA are impaired selectively in late CA1 LTP, but not earlier phases of LTP (Abel et al., 1997). These mutants have a specific deficit in the formation of contextual LTM, which can be phenocopied by blockade of protein synthesis in wild-type mice (Abel et al., 1997; Bourtchouladze et al., 1998). Furthermore, consistent with the late CA1 LTP hypothesis, dominant-negative CaM kinase IV transgenic mice and adenylyl cyclase 1 and 8 double null mutants have impaired late CA1 LTP and deficits in contextual memory formation (Wong et al., 1999; Kang et al., 2001). We showed that the Camkk2 null mutants specifically lack the late phase of CA1 LTP and LTM in the STFP task. This suggests that LTM in the STFP task requires late LTP. Consistent with this idea, zif268 null mutants are impaired selectively in late 
LTP in dentate gyrus and in LTM in the STFP task (Jones et al., 2001).

Here we also showed that the Camkk2 null mutants, with impaired late CA1 LTP, were not affected in the formation of contextual, trace fear, and passive avoidance LTM. Thus the late CA1 LTP does not correlate with these types of LTM. So could the LTM phenotype of all mutant lines discussed above have been caused by impairments in synaptic plasticity other than late CA1 LTP? It is possible, but recently different types of late CA1 LTP have been discovered (Patterson et al., 2001; Pittenger et al., 2002). Some of these types might not require the CaM kinase kinase $\beta$ isoforms and could be important for the formation of contextual, trace fear, and passive avoidance LTM.

\section{Spatial and contextual LTM involve different signaling processes in the hippocampus}

It is well established that CREB needs to be activated for the formation of different types of hippocampal LTM. However, it is not known whether for every type of LTM the same signaling pathway leads to the activation of CREB. Earlier studies with the Camk4 null mutants may imply that different CREB activations in the hippocampus underlie the consolidation of spatial and contextual LTM. The Camk4 null mutants are impaired specifically in the formation of contextual LTM, and they have normal spatial memory formation (Ho et al., 2000; Wei et al., 2002). However, the dominant-negative CaM kinase IV transgenic mice are impaired in both contextual and spatial memory formation (Kang et al., 2001).

We have shown that the CaM kinase kinase $\beta$ isoforms are required for spatial training-induced CREB activation in the hippocampus and for spatial memory formation. Surprisingly, we found that the CaM kinase kinase $\beta$ isoforms are not essential for the formation of contextual LTM and passive avoidance LTM. Both contextual and passive avoidance memory require the amygdala, but additionally the hippocampus is essential. Blockade of hippocampal protein synthesis, as well as inhibition of CRE-mediated transcription, in the hippocampus impairs contextual and passive avoidance LTM (Taubenfeld et al., 2001; Athos et al., 2002; Debiec et al., 2002). Thus CREB activation in the hippocampus is required for the formation of spatial, contextual, and passive avoidance LTM. Our finding that the lack of the CaM kinase kinase $\beta$ isoforms impairs CREB activation during spatial memory formation, but does not affect the formation of contextual and passive avoidance LTM, suggests that different signaling processes underlie the formation of these types of hippocampal LTM. The formation of contextual and passive avoidance LTM does not require activation of CREB by the CaM kinase kinase $\beta$ isoforms. Other signaling pathways could activate CREB for these types of LTM; alternatively, the activation of CREB may not be needed.

\section{References}

Abel T, Nguyen PV, Barad M, Deuel TAS, Kandel ER, Bourtchouladze R (1997) Genetic demonstration of a role for PKA in the late phase of LTP and in hippocampus-based long-term memory. Cell 88:615-626.

Alvarez P, Lipton PA, Melrose R, Eichenbaum H (2001) Differential effects of damage within the hippocampal region on memory for a natural, nonspatial odor-odor association. Learn Mem 8:79-86.

Anagnostaras SG, Gale GD, Fanselow MS (2001) Hippocampus and contextual fear conditioning: recent controversies and advances. Hippocampus 11:8-17.

Anderson KA, Means RL, Huang Q-H, Kemp BE, Goldstein EG, Selbert MA, Edelman AM, Fremeau RT, Means AR (1998) Components of a calmodulin-dependent protein kinase cascade. J Biol Chem 273:31880-31889.
Angelo M, Plattner F, Irvine EE, Giese KP (2003) Improved reversal learning and altered fear conditioning in transgenic mice with regionally restricted p25 expression. Eur J Neurosci 18:423-431.

Athos J, Impey S, Pineda VV, Chen X, Storm DR (2002) Hippocampal CREmediated gene expression is required for contextual memory formation. Nat Neurosci 5:1119-1120.

Bilang-Bleuel A, Rech J, De Carli S, Holsboer F, Reul JM (2002) Forced swimming evokes a biphasic response in CREB phosphorylation in extrahypothalamic limbic and neocortical brain structures in the rat. Eur J Neurosci 15:1048-1060.

Bito H, Deisseroth K, Tsien RW (1996) CREB phosphorylation and dephosphorylation: a $\mathrm{Ca}^{2+}$ - and stimulus duration-dependent switch for hippocampal gene expression. Cell 87:1203-1214.

Bliss TVP, Collingridge GL (1993) A synaptic model of memory: long-term potentiation in the hippocampus. Nature 351:31-39.

Blum S, Moore AN, Adams F, Dash PK (1999) A mitogen-activated protein kinase cascade in the CA1/CA2 subfield of the dorsal hippocampus is essential for long-term spatial memory. J Neurosci 19:3535-3544.

Bourtchouladze R, Frenguelli B, Blendy J, Cioffi D, Schütz G, Silva AJ (1994) Deficient long-term memory in mice with a targeted disruption of the cAMP-responsive element binding protein. Cell 79:59-68.

Bourtchouladze R, Abel T, Berman N, Gordon R, Lapidus K, Kandel ER (1998) Different training procedures recruit either one or two critical periods for contextual memory consolidation, each of which requires protein synthesis and PKA. Learn Mem 5:365-374.

Bunsey M, Eichenbaum H (1995) Selective damage to the hippocampal region blocks long-term retention of a natural and nonspatial stimulusstimulus association. Hippocampus 5:546-556.

Chen C, Tonegawa S (1997) Molecular genetic analysis of synaptic plasticity, activity-dependent neural development, learning, and memory in the mammalian brain. Annu Rev Neurosci 20:157-184.

Cho YH, Friedman E, Silva AJ (1999) Ibotenate lesions of the hippocampus impair spatial learning but not contextual fear conditioning in mice. Behav Brain Res 98:77-87.

Clark RE, Broadbent NJ, Zola SM, Squire LR (2002) Anterograde amnesia and temporally graded retrograde amnesia for a nonspatial memory task after lesions of hippocampus and subiculum. J Neurosci 22:4663-4669.

Colombo PJ, Brightwell JJ, Countryman RA (2003) Cognitive strategyspecific increases in phosphorylated cAMP response element binding protein and $c$-fos in the hippocampus and dorsal striatum. J Neurosci 23:3547-3554.

Corcoran EE, Means AR (2001) Defining $\mathrm{Ca}^{2+} /$ calmodulin-dependent protein kinase cascades in transcriptional regulation. J Biol Chem 276:2975-2978.

Costa RM, Yang T, Huynh DP, Pulst SM, Viskochil DH, Silva AJ, Brannan CI (2001) Learning deficits, but normal development and tumor predisposition, in mice lacking exon 23a of Nf1. Nat Genet 27:399-405.

Debiec J, LeDoux JE, Nader K (2002) Cellular and systems reconsolidation in the hippocampus. Neuron 36:527-538.

Frey U, Krug M, Reymann KG, Matthies H (1988) Anisomycin, an inhibitor of protein synthesis, blocks late phases of LTP phenomena in the hippocampal CA1 region in vitro. Brain Res 452:57-65.

Gallagher M, Burwell R, Burchinal M (1993) Severity of spatial learning impairment in aging: development of a learning index for performance in the Morris water maze. Behav Neurosci 107:618-626.

Gass P, Wolfer DP, Balschun D, Rudolph D, Frey U, Lipp H-P, Schütz G (1998) Deficits in memory tasks of mice with CREB mutations depend on gene dosage. Learn Mem 5:274-288.

Gerlai R (1996) Gene-targeting studies of mammalian behavior: is it the mutation or the background phenotype? Trends Neurosci 19:177-181.

Giese KP, Fedorov NB, Filipkoski RK, Silva AJ (1998) Autophosphorylation at $\mathrm{Thr}^{286}$ of the $\alpha$ calcium-calmodulin kinase II in LTP and learning. Science 279:870-873.

Guzowski JF, McGaugh JL (1997) Antisense oligonucleotide-mediated disruption of hippocampal cAMP response element binding protein levels impairs consolidation of memory for water maze training. Proc Natl Acad Sci USA 94:2693-2698.

Ho N, Liauw JA, Blaeser F, Wei F, Hanissian S, Muglia LM, Wozniak DF, Nardi A, Arvin KL, Holtzman DM, Linden DJ, Zhuo M, Muglia LJ, Chatila TA (2000) Impaired synaptic plasticity and cAMP response element-binding protein activation in $\mathrm{Ca}^{2+} /$ calmodulin-dependent protein kinase type IV/Gr-deficient mice. J Neurosci 20:6459-6472. 
Hsu LS, Chen GD, Lee LS, Chi CW, Cheng JF, Chen JY (2001) Human $\mathrm{Ca}^{2+} /$ calmodulin-dependent protein kinase kinase $\beta$ gene encodes multiple isoforms that display distinct kinase activity. J Biol Chem 276:31113-31123.

Huerta PT, Sun LD, Wilson MA, Tonegawa S (2000) Formation of temporal memory requires NMDA receptors within CA1 pyramidal neurons. Neuron 25:473-480.

Impey S, Smith DM, Obrietan K, Donahue R, Wade C, Storm DR (1998) Stimulation of cAMP response element (CRE)-mediated transcription during contextual learning. Nat Neurosci 1:595-601.

Jones MW, Errington ML, French PJ, Fine A, Bliss TVP, Garel S, Charnay P, Bozon B, Laroche S, Davis S (2001) A requirement for the immediate early gene Zif268 in the expression of late LTP and long-term memories. Nat Neurosci 4:289-296.

Kang H, Sun LD, Atkins CM, Soderling TR, Wilson MA, Tonegawa S (2001) An important role of neural activity-dependent CaMKIV signaling in the consolidation of long-term memory. Cell 106:771-783.

Kasahara J, Fukunaga K, Miyamoto E (2001) Activation of calcium/ calmodulin-dependent protein kinase IV in long-term potentiation in the rat hippocampal CA1 region. J Biol Chem 276:24044-24050.

Kida S, Josselyn SA, de Ortiz SP, Kogan JH, Chevere I, Masushige S, Silva AJ (2002) CREB required for the stability of new and reactivated fear memories. Nat Neurosci 5:348-355.

Kim JJ, Fanselow MS (1992) Modality-specific retrograde amnesia of fear. Science 256:675-677.

Kimura Y, Corcoran EE, Eto K, Gengyo-Ando K, Muramatsu MA, Kobayashi R, Freedman JH, Mitani S, Hagiwara M, Means AR, Tokumitsu H (2002) A CaMK cascade activates CRE-mediated transcription in neurons of Caenorhabditis elegans. EMBO Rep 3:962-966.

Kitani T, Okuno S, Fujisawa H (1997) Molecular cloning of $\mathrm{Ca}^{2+} /$ calmodulin-dependent protein kinase kinase $\beta$. J Biochem 122:243-250.

Kogan JH, Frankland PW, Blendy JA, Coblentz J, Marowitz Z, Schütz G, Silva AJ (1997) Spaced training induces normal long-term memory in CREB mutant mice. Curr Biol 7:1-11.

Lonze BE, Ginty DD (2002) Function and regulation of CREB family transcription factors in the nervous system. Neuron 35:605-623.

McEchron MD, Bouwmeester H, Tseng W, Weiss C, Disterhoft JF (1998) Hippocampectomy disrupts auditory trace fear conditioning and contextual fear conditioning in the rat. Hippocampus 8:638-646.

Mizuno M, Yamada K, Maekawa N, Saito K, Seishima M, Nabeshima T (2002) CREB phosphorylation as a molecular marker of memory processing in the hippocampus for spatial learning. Behav Brain Res 133:135-141.

Morris RGM, Garrud P, Rawlins JNP, O'Keefe J (1982) Place navigation impaired in rats with hippocampal lesions. Nature 297:681-683.

Nagy A, Rossant J, Nagy R, Abramow-Newerly W, Roder JC (1993) Derivation of completely cell culture-derived mice from early-passage embryonic stem cells. Proc Natl Acad Sci USA 90:8424-8428.

Nakamura Y, Okuno S, Kitani T, Otake K, Sato F, Fujisawa H (2001) Immunohistochemical localization of $\mathrm{Ca}^{2+} /$ calmodulin-dependent protein kinase kinase $\beta$ in the rat central nervous system. Neurosci Res 39:175-188.

Nguyen PV, Abel T, Kandel ER (1994) Requirement of a critical period of transcription for induction of a late phase of LTP. Science 265:1104-1107.
Osoegawa K, Tateno M, Woon PY, Frengen E, Mammoser AG, Catanese JJ, Hayashizaki Y, de Jong PJ (2000) Bacterial artificial chromosome libraries for mouse sequencing and functional analysis. Genome Res 10:116-128.

Patterson SL, Pittenger C, Morozov A, Martin KC, Scanlin H, Drake C, Kandel ER (2001) Some forms of cAMP-mediated long-lasting potentiation are associated with release of BDNF and nuclear translocation of phospho-MAP kinase. Neuron 32:123-140.

Phillips RG, LeDoux JE (1992) Differential contribution of amygdala and hippocampus to cued and contextual fear conditioning. Behav Neurosci 106:274-285.

Pittenger C, Huang YY, Paletzki RF, Bourtchouladze R, Scanlin H, Vronskaya S, Kandel ER (2002) Reversible inhibition of CREB/ATF transcription factors in region CA1 of the dorsal hippocampus disrupts hippocampusdependent spatial memory. Neuron 34:447-462.

Rampon C, Tang YP, Goodhouse J, Shimizu E, Kyin M, Tsien JZ (2000) Enrichment induces structural changes and recovery from nonspatial memory deficits in CA1 NMDAR1-knockout mice. Nat Neurosci 3:238-244.

Ribar TJ, Rodriguiz RM, Khiroug L, Wetsel WC, Augustine GJ, Means AR (2000) Cerebellar defects in $\mathrm{Ca}^{2+} /$ calmodulin kinase IV-deficient mice. J Neurosci 20:RC107(1-5).

Sakagami H, Umemiya M, Saito S, Kondo H (2000) Distinct immunohistochemical localization of two isoforms of $\mathrm{Ca}^{2+} /$ calmodulin-dependent protein kinase kinases in the adult rat brain. Eur J Neurosci 12:89-99.

Selcher JC, Atkins CM, Trzaskos JM, Paylor R, Sweatt JD (1999) A necessity for MAP kinase activation in mammalian spatial learning. Learn Mem 6:478-490.

Silva AJ, Giese KP (1994) Plastic genes are in! Curr Opin Neurobiol 4:413-420.

Takemoto-Kimura S, Terai H, Takamoto M, Ohmae S, Kikumura S, Segi E, Arakawa Y, Furuyashiki T, Narumiya S, Bito H (2003) Molecular cloning and characterization of CLICK-III/CaMKI $\gamma$, a novel membraneanchored neuronal $\mathrm{Ca}^{2+} /$ calmodulin-dependent protein kinase (CaMK). J Biol Chem 278:18597-18605.

Taubenfeld SM, Wiig KA, Bear MF, Alberini CM (1999) A molecular correlate of memory and amnesia in the hippocampus. Nat Neurosci 2:309-310.

Taubenfeld SM, Milekic MH, Monti B, Alberini CM (2001) The consolidation of new but not reactivated memory requires hippocampal C/EBP $\beta$. Nat Neurosci 4:813-818.

Tokumitsu H, Enslen H, Soderling TR (1995) Characterization of $\mathrm{Ca}^{2+}$ / calmodulin-dependent protein kinase cascade. J Biol Chem 270:19320-19324.

Wei F, Qiu CS, Liauw J, Robinson DA, Ho N, Chatila T, Zhuo M (2002) Calcium calmodulin-dependent protein kinase IV is required for fear memory. Nat Neurosci 5:573-579.

Winocur G, McDonald RM, Moscovitch M (2001) Anterograde and retrograde amnesia in rats with large hippocampal lesions. Hippocampus 11:18-26.

Wong ST, Athos J, Figueroa XA, Pineda VV, Schaefer ML, Chavkin CC, Muglia LJ, Storm DR (1999) Calcium-stimulated adenylyl cyclase activity is critical for hippocampus-dependent long-term memory and late phase LTP. Neuron 23:787-798. 